\title{
Over-Time Changes in Adjustment and Competence among Adolescents from Authoritative, Authoritarian, Indulgent, and Neglectful Families
}

\section{Laurence Steinberg}

Temple University

\author{
Susie D. Lamborn
}

University of West Florida

\section{Naney Darling}

Temple University

\author{
Nina S. Mounts \\ University of Illinois
}

\section{Sanford M. Dornbusch}

Stanford University

\begin{abstract}
Steinberg, Laurence; Lamborn, Susie D.; Darling, Nancy; Mounts, Nina S.; and Dornbusch, SANFORD M. Over-Time Changes in Adjustment and Competence among Adolescents from Authoritative, Authoritarian, Indulgent, and Neglectful Families. CHILD DEveloPMENT, 1994, 65, 754-770. In a previous report, we demonstrated that adolescents' adjustment varies as a function of their parents' style (e.g., authoritative, authoritarian, indulgent, neglectful). This l-year followup was conducted in order to examine whether the observed differences are maintained over time. In 1987, an ethnically and socioeconomically heterogeneous sample of approximately 2,300 14-18-year-olds provided information used to classify the adolescents' families into 1 of 4 parenting style groups. That year, and again 1 year later, the students completed a battery of standardized instruments tapping psychosocial development, school achievement, internalized distress, and behavior problems. Differences in adjustment associated with variations in parenting are either maintained or increase over time. However, whereas the benefits of authoritative parenting are largely in the maintenance of previous levels of high adjustment, the deleterious consequences of neglectful parenting continue to accumulate.
\end{abstract}

An extensive literature on socialization practices and their effects provides consistent evidence that parental warmth, inductive discipline, nonpunitive punishment practices, and consistency in child rearing are each associated with positive developmental outcomes in children (Maccoby \& Martin, 1983). Since the early 1970s, this constellation of practices has come to be known as "authoritative" parenting, one of several prototypic styles of parenting identified in the seminal studies of Diana Baum- rind (1967, 1971). Children who are raised in authoritative homes score higher than their peers from authoritarian, indulgent, or neglectful homes on a wide variety of measures of competence, achievement, social development, self-perceptions, and mental health (Maccoby \& Martin, 1983). Several recent studies have applied Baumrind's model to explain variations in patterns of adolescent development, including academic achievement, psychosocial development, behavior problems, and psychological symptoms

Preparation of this manuscript was supported by grants from the Lilly Endowment and the William T. Grant Foundation. The study on which this report is based was supported by grants from the U.S. Department of Education, through the National Center on Effective Secondary Schools, and the Spencer Foundation. Address correspondence to the first author at the Department of Psychology, Temple University, Philadelphia, PA 19122. 
(e.g., Dornbusch, Ritter, Liederman, Roberts, \& Fraleigh, 1987; Lamborn, Mounts, Steinberg, \& Dornbusch, 1991; Steinberg, Elmen, \& Mounts, 1989; Steinberg, Lamborn, Dornbusch, \& Darling, 1992; Steinberg, Mounts, Lamborn, \& Dornbusch, 1991), and these reports find that adolescents, like their younger counterparts, benefit from authoritative parenting.

In a previous report (Lamborn et al., 1991), we provided evidence for the utility, in research on parental socialization and adolescent adjustment, of a fourfold parenting typology based on Baumrind's framework and set forth by Maccoby and Martin (1983). In that earlier study, the families of approximately 4,000 14-18-year-olds were classified into one of four groups (authoritative, authoritarian, indulgent, or neglectful) on the basis of adolescents' ratings of their parents on two dimensions: acceptance/ involvement and strictness/supervision. Analysis of adolescents' scores on four sets of outcomes-psychosocial development, school achievement, internalized distress, and problem behavior-indicated numerous differences among adolescents from authoritative, authoritarian, indulgent, and neglectful homes. Specifically, adolescents from authoritative homes scored highest, and adolescents from neglectful homes lowest, on the majority of indices of adjustment. Adolescents in either the authoritarian or the indulgent group showed a mixture of positive and negative traits, with adolescents from authoritarian homes scoring reasonably well on measures of school achievement and deviance but relatively poorly on measures of self-reliance and self-conceptions, and adolescents from indulgent homes scoring relatively poorly with respect to school engagement, drug and alcohol use, and school misconduct but relatively well on measures of social competence and self-confidence. In general, these patterns did not vary as a function of adolescent age, gender, ethnicity, or family background.

The present article presents data from a 1-year follow-up of these adolescents. The short-term longitudinal follow-up is important for several reasons. First, although the cross-sectional findings reported in the earlier article are consistent with other research and theory on adolescent socialization, the observed correlations between adolescent behavior and parenting practices could be due to the influence of young people on their parents, rather than the reverse (e.g., Bell, 1968). Although some of the specific findings are difficult to construe from within this causal framework (e.g., it is hard to imagine that parents respond to adolescent drug use with increased indulgence), many are not (e.g., it is quite plausible that parents respond to high achievement with authoritativeness). Indeed, Steinberg et al. (1989) report that psychosocial maturity during early adolescence is likely to evoke parental warmth, rather than the reverse. A shortterm longitudinal design permits a more careful, if still imperfect, assessment of the impact of parenting practices on adolescent development.

Second, as will be made clear in subsequent sections of this article, the short-term longitudinal design employed here helps to rebut claims that observed correlations between adolescent adjustment and parenting practices are due either to third variables or to common source or method variance-a common criticism of socialization research that employs survey data (in the present study, both the classification of parents and the assessment of adolescent adjustment derive from adolescents' reports). Specifically, by using adolescents' initial adjustment scores as covariates in analyses designed to predict their later adjustment from their parents' practices, we greatly reduce the common method and source variance shared between the adjustment and parenting measures.

Finally, and most important, even if the differences among the adolescents reported in our earlier article were actually due to differences in parental practices, any differences we observed among the youngsters in our sample might have existed long before adolescence and simply remained in place over time. The short-term longitudinal design of the present study permits us to ask whether there are continuing benefits or liabilities of particular approaches to parenting during the middle adolescent years and to report on the 1-year developmental trajectories of youngsters from different home environments. Such information is exceedingly useful to both practitioners and parents, who understandably want to know if parenting practices continue to "make a difference" once the child has reached high school.

\section{Method}

\section{Sample}

Our sample is drawn from the student bodies of nine high schools in Wisconsin and northern California. The schools were 


\section{Child Development}

selected to yield a sample of students from different socioeconomic brackets, a variety of ethnic backgrounds (African-, Asian-, European-, and Hispanic-American), different family structures (e.g., intact, divorced, and remarried), and different types of communities (urban, suburban, and rural). Data for the present analyses were collected during the 1987-88 and 1988-89 school years via self-report surveys filled out by the students on 2 days of survey administration each school year. Because of its length, the survey was divided into two parts.

\section{Procedure}

Recent reports suggest that the use of "active consent" procedures in research on adolescents and their families (i.e., procedures requiring active parental written consent in order for their adolescents to participate in the research) may result in sampling biases that overrepresent well-functioning teenagers and families (e.g., Weinberger, Tublin, Ford, \& Feldman, 1990). Although groups of participants and nonparticipants generated through such consent procedures may be comparable demographically (the dimension along which investigators typically look for evidence of selective participation), the procedure screens out a disproportionate number of adolescents who have adjustment problems and/or family difficulties. Because we were interested in studying "neglectful" as well as more involved families in this research, and because many of our outcome measures are in the domain of adjustment, we were concerned that employing the standard active consent procedure (in which both parents and adolescents are asked to return signed consent forms to their child's school) would bias our sample toward more involved-and, presumably, better functioning-families.

After considering the age of our respondents and their ability to provide informed consent, and with the support of the administrators of our participating schools, the school districts' research review committees, representatives of the U.S. Department of Education (our chief funding agent), and our own institutions' human subjects committees, we decided to employ a consent procedure that requested "active" informed consent from the adolescents, but "passive" informed consent from their parents. All parents in the participating schools were informed, by first-class mail, of the date and nature of our study well in advance of the scheduled questionnaire administration. (We provided schools with letters in stamped, unaddressed envelopes to be mailed by school officials in order to protect the privacy of the families.) Parents were asked to call or write to their child's school or our research office if they did not want their child to participate in the study. Fewer than $1 \%$ of the adolescents in each of the target schools had their participation withheld by their parents.

All of the students in attendance on each day of testing were invited to participate in the study and asked to complete the questionnaires. Informed consent was obtained from all participating students. For each questionnaire administration, out of the total school populations, approximately $5 \%$ of the students chose not to participate (or had their participation withheld by parents), approximately $15 \%$ were absent from school on the day of questionnaire administration (this figure is comparable to national figures on daily school attendance), and approximately $80 \%$ provided completed questionnaires. In the 1987-88 school year, 11,669 students participated in the study. In the 1988-89 school year, 11,248 students participated. Our longitudinal study sample across the 2 years included approximately 6,357 students. Subject attrition over the 1-year period was due primarily to graduation (the 1987-88 sample included 2,538 seniors), dropping out of school, or movement out of the school district $(17 \%$ of the sample reported having attended more than one high school, indicative of the high degree of mobility within the population studied).

The use of this consent procedure has both costs and benefits. On the positive side, we have responses from a more representative sample of adolescents, including adolescents whose parents are not involved in school, than one would otherwise have. On the negative side, however, our consent procedure does not permit us to obtain information from an equally representative set of parents. Rather than limit our study to the well-functioning parents who volunteer to participate in research of this sort, we have chosen to collect information on parenting practices from the adolescents themselves.

Characteristics of the study sample are presented in the first column of Table 1. As the table indicates, the sample is evenly divided among males and females and among ninth, tenth, and eleventh graders. The sample is quite diverse with respect to other demographic variables: more than $40 \%$ of the respondents are from an ethnic minority 
TABLE 1

Demographic Characteristics of the Total $(N=6,902)$ AND STUdY $(N=2,353)$ SAMples

\begin{tabular}{|c|c|c|}
\hline & $\begin{array}{c}\text { Total } \\
\text { Sample } \\
(\%)\end{array}$ & $\underset{(\%)}{\text { Study }}$ \\
\hline \multicolumn{3}{|l|}{ Ethnicity: } \\
\hline African-American ….................. & 8.6 & 9.1 \\
\hline European-American .............. & 60.7 & 62.2 \\
\hline Asian-American …………........... & 15.1 & 14.8 \\
\hline Hispanic-American ……........... & . 15.5 & 13.9 \\
\hline \multicolumn{3}{|c|}{ Sex: } \\
\hline Male & . 49.9 & 48.2 \\
\hline 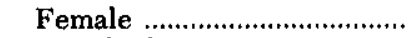 & . 50.1 & 51.8 \\
\hline \multicolumn{3}{|l|}{ Parental education: } \\
\hline$<$ College & . 28.5 & 29.3 \\
\hline College graduate & . 71.5 & 70.7 \\
\hline \multicolumn{3}{|c|}{ Family structure: } \\
\hline Intact & 70.8 & 70.9 \\
\hline 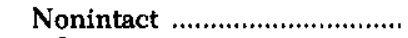 & . 29.2 & 29.1 \\
\hline \multicolumn{3}{|l|}{ Graduation year: } \\
\hline 1989 & . 31.9 & 33.3 \\
\hline 1990 & . 33.7 & 32.7 \\
\hline 1991 & . 34.4 & 34.1 \\
\hline
\end{tabular}

group, nearly one-third are from singleparent households or stepfamilies, and nearly one-third come from homes in which the parents have not attended school beyond the twelfth grade.

\section{Measures}

Of interest in the present analyses are several demographic variables, two parenting indices that were used to construct the family types, and the four sets of outcome variables.

Demographic variables.-Students provided information on their background and current family situation. All respondents indicated their sex, year in school (used as a proxy for age), ethnic identification (ultimately coded as African-American, AsianAmerican, Hispanic-American, non-Hispanic white, or other), family structure (two natural parents, single-parent, stepfamily, other), and the amount of education completed by each parent residing with them. Parental education was coded as a two-level variable (less than college completion or college completion and higher). In previous reports, we have shown that the relations between parenting style and the aspects of adolescent adjustment examined here do not vary as a function of child age, socioeconomic status, gender, or family structure (Lamborn et al., 1991; Steinberg, Lamborn, Dornbusch, \& Darling, 1992; Steinberg et al., 1991). We have, however, found that some of these relations vary as a function of ethnicity (Steinberg, Lamborn, Dornbusch, \& Darling, 1992; Steinberg et al., 1991). Accordingly, the interactive effects of parenting style and ethnicity are examined in the present report.

Parenting style.-The index of parenting style was developed to approximate the categorical scheme suggested by Baumrind (1971) and Maccoby and Martin (1983). The first year's questionnaires contained many items on parenting practices that were taken or adapted from existing measures (e.g., Dornbusch, Carlsmith, Bushwall, Ritter, Liederman, Hastork, \& Gross, 1985; Patterson \& Stouthamer-Loeber, 1984; Rodgers, 1966) or developed for the program of work. (In view of other research [e.g., Hetherington et al., 1992] indicating very high 1-year stability coefficients for similar measures of parenting, these questions were not repeated at the 1-year follow-up.) Adolescents completed these measures vis-à-vis both parents in two-parent households (in which ratings for mother and father were averaged) and vis-a-vis mothers in single-parent homes. (Baumrind [1991] reports that there is considerable convergence between mothers' and fathers' ratings.) Based on the previous work of Steinberg et al. (1989), a number of items were selected to correspond with several dimensions of parenting identified in earlier studies, and these items were subjected to exploratory factor analyses using an oblique rotation (we had no reason to assume that the dimensions are orthogonal). As in other studies of parenting practices (see Schaefer, 1965; Steinberg, 1990), three factors emerged: acceptance/involvement, strictness/supervision, and psychological autonomy.

Our previous work has indicated that the psychological autonomy dimension appears to be important in defining authoritativeness but less so in differentiating among authoritative, authoritarian, indulgent, and neglectful families. Accordingly, scores on the acceptance/involvement and strictness/ supervision dimensions were used in the present investigation to assign families to one of four groups, as outlined below. The acceptance/involvement scale measures the extent to which the adolescent perceives his or her parents as loving, responsive, and involved (sample items: "I can count on [them] to help me out if I have some kind of problem"; "When he wants me to do something, he explains why"; 10 items, $\alpha=$ 
$.72, M=.81, \mathrm{SD}=.11$, range $=.25$ to 1.0 ), The strictness/supervision scale assesses parental monitoring and supervision of the adolescent (sample items: "How much do your parents try to know where you go at night?"; "My parents know exactly where I am most afternoons after school"; nine items, $\alpha=.76, M=.74, \mathrm{SD}=.13$, range $=$ .30 to 1.0 ). In this sample, the dimensions are modestly intercorrelated $(r=.34, p<$ $.001)$. For each of these scales, several of the items are in a true/false format, while others are Likert scaled on a three-point scale; in the formation of the composite indices for acceptance and strictness, items were weighted to adjust for differences in scaling. A complete listing of the items from each scale appears in Lamborn et al. (1991).

Historically, researchers have applied both typological and dimensional approaches to the study of socialization in the family. As we have argued elsewhere (Darling \& Steinberg, 1993), the two approaches have different theoretical orientations and are based on different assumptions. In the typological tradition, the general pattern, organization, or climate of parenting is of primary interest, and the assessment of specific parenting practices or dimensions (such as acceptance or strictness) is done for heuristic purposes, as a means of providing a window on the overall parenting environment. In the dimensional tradition, in contrast, different aspects of the parent-child relationship are assessed in order to test specific hypotheses about their relation (separately and jointly) to child adjustment. Each tradition has merit, and a decision to use one versus the other should be made on theoretical grounds.

We decided to use a typological approach in the present study-that is, to use the acceptance and strictness scales to assign families to categories, rather than to treat these dimensions as continuous variablesfor two reasons. First, the decision reflects our interest in examining the specific theoretical framework set forth by Baumrind (1971) and later elaborated by Maccoby and Martin (1983). Baumrind's theory, which has had considerable impact on the study of socialization for nearly 3 decades, is a theory about types, not about specific parenting practices. Second, the typological approach is more appropriate for charting the shortterm developmental trajectories of adolescents reared in different parenting environments.
Four parenting categories were defined by trichotomizing the sample on acceptance and on strictness and examining families' scores on the two variables simultaneously. Following Maccoby and Martin (1983), authoritative families $(N=817)$ were those who scored in the upper tertiles on both acceptance/involvement and strictness/supervision, whereas neglectful families $(N=$ 838 ) were in the lowest tertiles on both variables. Authoritarian families $(N=451)$ were in the lowest tertile on involvement but in the highest tertile on strictness. Indulgent families $(N=251)$ were in the highest tertile on involvement but in the lowest tertile on strictness. Families who scored in the middle tertile on either of the dimensions were excluded from the analysis, in order to ensure that the four groups of families represented distinct categories. This procedure was followed in the analysis of the crosssectional data (Lamborn et al., 1991) and is repeated here for comparability.

The use of the tertile split procedure to assign families to the parenting groups, rather than assigning families on the basis of predetermined cutoffs, results in a categorization of families that is admittedly samplespecific. While we can be confident, for example, that the families in our "indulgent" category are indeed relatively more indulgent (i.e., more accepting and less strict) than the other families in the sample, we do not know whether the families we have labeled "indulgent" would be considered "indulgent" within a different population or at a different point in historical time. Thus, it is important to bear in mind that the designation of families as one type or another relative to their counterparts is done for heuristic, not diagnostic, purposes.

Because each year's survey was divided into two portions administered on separate testing days, there were some students in the longitudinal sample who completed only one of the two parts of the survey in a given year. This occasionally presented a problem in the scoring of composite measures that drew on both survey parts. In general, we handled instances of missing data conservatively, calculating composite scores only when respondents had answered $80 \%$ of the necessary items. As a result of this procedure, however, our $N s$ varied from analysis to analysis (depending on the variables examined), although in no case were less than 1,000 subjects included in any analysis. (Because this is a longitudinal study in which subjects' prior scores are used as controls in 
the analysis, this attrition is less problematic than it otherwise might be.) Nonetheless, because absence from school was an important cause of missing data, the sample on whom the main data analyses were performed is in all likelihood relatively more engaged in school (and, presumably, better functioning in other respects) than were the student bodies in general. One important implication of this is that our estimates of effects are likely to be overly conservative: Because variability in our outcome measures is probably constrained, the observed relations between outcomes and predictors are attenuated.

Although the tertile split procedure permits us to be more confident that the four categories of families actually represent different types (thereby strengthening the study's internal validity), the procedure eliminates from the analysis a large number of families whose parenting is "average" (thereby weakening the study's external validity). Thus, while our focus on the extreme groups in our sample may provide a clearer test of the theory, the approach we have chosen limits the generalizability of our findings. However, as Table 1 indicates, the sample of families scoring in the upper or lower tertiles on the parenting variables is demographically comparable to the overall project sample, suggesting that we have not selectively excluded any demographic subgroups through the use of the tertile split procedure. Table 2 provides information on the sizes of each of the four parenting groups as well as each group's mean and standard deviations on the acceptance and strictness scales.

Outcome variables.-As in the crosssectional analyses, four sets of outcome variables were examined: psychosocial development, academic competence, internalized distress, and problem behavior. Table 3 presents means and standard deviations on the outcome variables for the entire sample (including adolescents who were not classified into one of the four parenting groups). Table 4 presents intercorrelations among the outcome variables. With the exception of grade point average, all outcome variables have been scaled on four-point Likert scales, with 1 as low (e.g., "never," "strongly disagree," "not like me") and 4 as high (e.g., "frequently," "strongly agree," "very much like me"). In the case of grade point average, scores were converted to the standard 4.0 metric and could range from 0 (all F's) to 4.0 (all A's). In general, the pattern of intercorrelations (Table 4) supports our distinguishing among the four sets of outcomes and between the various indicators within each set, although there is some overlap between certain aspects of psychosocial development and certain aspects of school competence. Correlations between the two measures of internalized distress and among the three measures of problem behavior are among the highest in the matrix.

The three indices of psychosocial development include the social competence subscale of the Adolescent Self-Perception Profile (Harter, 1982) and two subscales from Greenberger's Psychosocial Maturity Inventory-work orientation and self-reliance (Form D; Greenberger, Josselson, Knerr, \& Knerr, 1974). The social competence measure $(\alpha=.78)$ includes five items that ask students whether they perceive themselves as popular, as having many friends, and as making friends easily. The participants are asked to read two alternatives (e.g., "Some teenagers feel that they are socially accepted, but other teenagers wish that more people their age would accept them") and choose the one that is more like themselves. The work orientation $(\alpha=.73)$ and self-

TABLE 2

Sample Sizes and Means and Standard Deviations on Parental Involvement and Structness for the Four Groups of Adolescents

\begin{tabular}{|c|c|c|c|c|c|}
\hline & Total & Authoritative & Authoritarian & Indulgent & Neglectful \\
\hline Frequency ............. & 2,353 & 817 & 451 & 251 & 838 \\
\hline 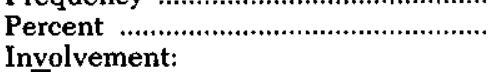 & 100 & 34.7 & 19.2 & 10.7 & 35.4 \\
\hline $\bar{X}$ & .79 & .93 & .70 & .92 & .67 \\
\hline SD & .14 & .03 & .07 & .03 & .08 \\
\hline \multicolumn{6}{|l|}{ Strictness: } \\
\hline $\bar{X} \ldots \ldots \ldots \ldots \ldots$ & .75 & .88 & .89 & .62 & .58 \\
\hline SD & .16 & .05 & .05 & .07 & .09 \\
\hline
\end{tabular}


TABLE 3

Mean Scones, Standard Deviations, and Ranges of Dependent Varuables at TIME 1 and TIME 2

\begin{tabular}{|c|c|c|c|}
\hline Variable & $\bar{X}$ & $\mathrm{SD}$ & Range \\
\hline \multicolumn{4}{|l|}{ Time 1: } \\
\hline Self-reliance ....... & 3.02 & .53 & $1-4$ \\
\hline Work orientation & 2.76 & .47 & $1-4$ \\
\hline Social self-competence ....................... & 2.99 & .47 & $1-4$ \\
\hline Grade point average & 2.85 & .72 & $0-4$ \\
\hline School orientation & 2.77 & .56 & $1-4$ \\
\hline Academic self-competence & 2.87 & .48 & $1-4$ \\
\hline 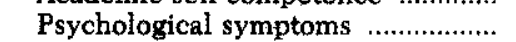 & 2.47 & .69 & $1-4$ \\
\hline Somatic symptoms & 2.14 & .54 & $1-4$ \\
\hline 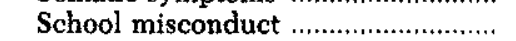 & 2.34 & .67 & $1-4$ \\
\hline Alcohol and drug use ....................... & 1.58 & .70 & $1-4$ \\
\hline 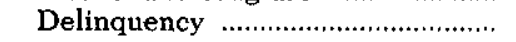 & 1.19 & .36 & $1-4$ \\
\hline \multicolumn{4}{|l|}{ Time 2: } \\
\hline Self-reliance & 2.99 & .34 & $1-4$ \\
\hline Work orientation & 2.72 & .30 & $1-4$ \\
\hline Social self-competence & 2.96 & .41 & $1-4$ \\
\hline Grade point average & 2.87 & .65 & $0-4$ \\
\hline School orientation & 2.73 & .32 & $1-4$ \\
\hline Academic self-competence & 2.92 & .38 & $1-4$ \\
\hline 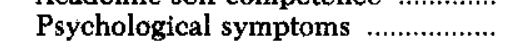 & 2.54 & .65 & $1-4$ \\
\hline Somatic symptoms & 2.20 & .52 & $1-4$ \\
\hline School misconduct & 2.27 & .53 & $1-4$ \\
\hline Alcohol and drug use & 1.55 & .58 & $1-4$ \\
\hline 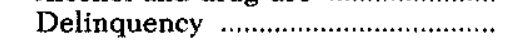 & 1.18 & .31 & $1-4$ \\
\hline
\end{tabular}

reliance $(\alpha=.81)$ subscales are each composed of 10 items. The work orientation scale measures the adolescent's pride in the successful completion of tasks. A sample item, reverse coded, is "I find it hard to stick to anything that takes a long time." The selfreliance scale measures the adolescent's feelings of internal control and ability to make decisions without extreme reliance on others. A sample item, reverse coded, is "luck decides most things that happen to me."

The three measures of school achievement include overall grade point average, the academic competence subscale of the Adolescent Self-Perception Profile (Harter, 1982), and a scale developed for this project that assesses the adolescent's orientation toward school. Respondents provided information on their current grade point average, on a nine-point scale ranging from "mostly A's" to "mostly F's"; scores were converted to correspond to a standard 4.0 grading scale. Self-reported grades are highly correlated with actual grades taken from official school records (Donovan \& Jessor, 1985; Dornbusch et al., 1987). The academic competence subscale $(\alpha=.73)$ includes five items asking about the student's perceptions of his or her intelligence in relation to classmates, ability to complete homework quickly, and capability in classwork. The measure of orientation toward school was derived from a set of items that assesses the student's feeling of attachment to school (Wehlage, Rutter, Smith, Lesko, \& Fernandez, 1989). Orientation toward school is a six-item scale ( $\alpha$ $=.69$ ) that emerged from a factor analysis of the total set of items. A sample item is "I feel satisfied with school because I'm learning a lot."

The set of three measures tapping problem behavior includes reports of involvement in drug and alcohol use, school misconduct, and delinquency. The measure of drug and alcohol use taps the frequency of involvement with cigarettes, alcohol, marijuana, and other drugs (five items, $\alpha=.86$ ) (Greenberger, Steinberg, \& Vaux, 1981). The measure of school misconduct assesses the frequency of such behaviors as cheating, copying homework, and tardiness (four items, $\alpha=.68$ ) (Ruggiero, 1984). The measure of delinquency assesses the frequency of such behaviors as carrying a weapon, theft, and getting into trouble with the po- 


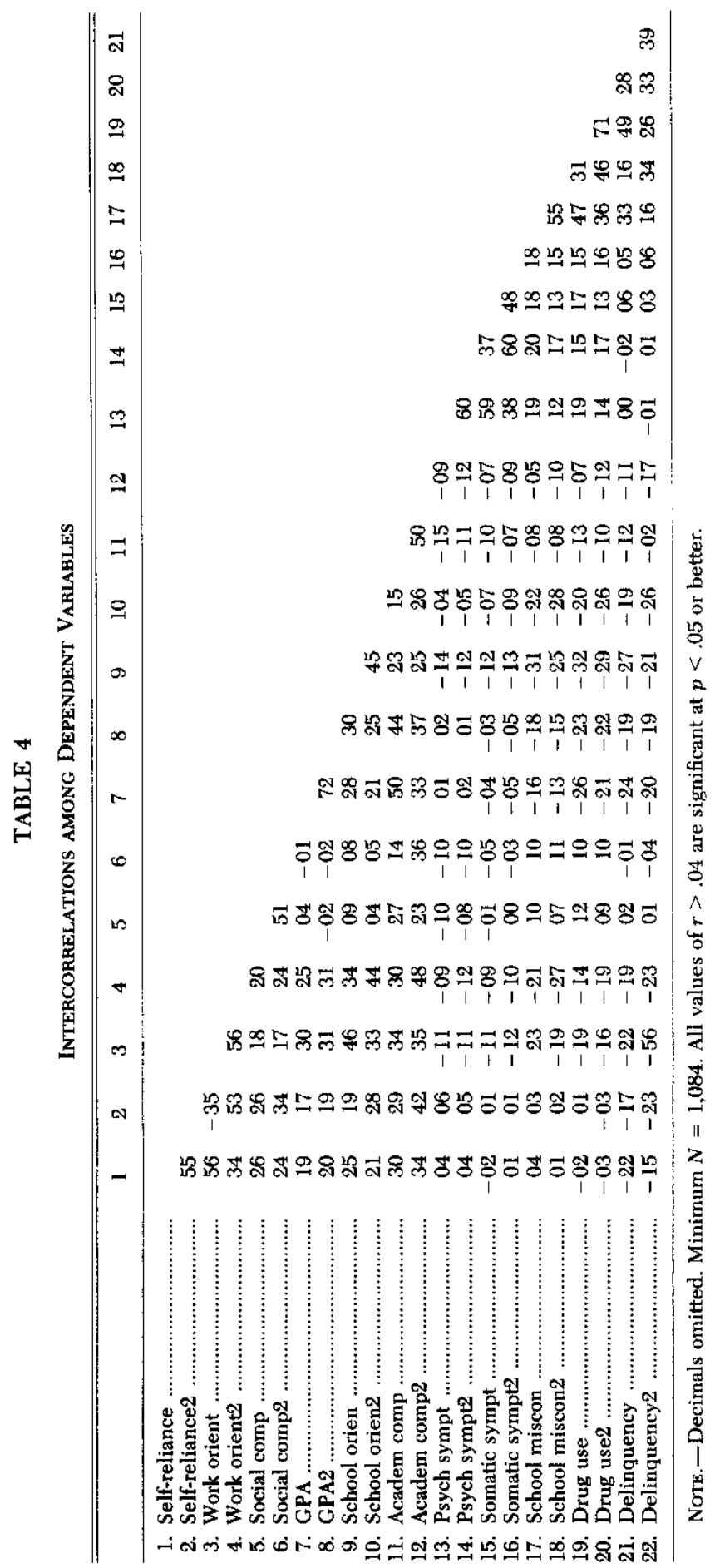




\section{Child Development}

lice (six items, $\alpha=.82$ ) (Gold, 1970). Although self-reports of deviant behavior are subject to both under- and over-reporting (see McCord, 1990), most researchers agree that these provide a closer approximation of youngsters' true involvement in deviant activity than do "official" reports (e.g., police records), and the practice of using self-report data in the study of adolescent deviance is widely established (see Gold, 1970; Jessor \& Jessor, 1977; McCord, 1990).

Two measures of internalized distress were derived from a 13-item version of the Depression Scale of the Center for Epidemiologic Studies (CES-D; Radloff, 1977). Results of a factor analysis suggested a somatic symptoms scale (seven items, $\alpha=67$ ), which includes items concerning the frequency of headaches, stomachaches, colds, and so forth; and a psychological symptoms scale (six items, $\alpha=.88$ ), which includes items concerning the frequency of anxiety, tension, and depression.

\section{Plan of Analyses}

There are a number of acceptable statistical techniques that one may employ in the analysis of short-term longitudinal data. $\mathrm{Be}$ cause preliminary analyses of the present data indicated fairly consistent effects of regression to the mean, it was necessary to perform analyses that took this effect into account. One such procedure is analysis of covariance (ANCOVA) in which the dependent variable is the change in the outcome of interest and the covariate is the relevant Time 1 score on the outcome (Laird, 1983). Accordingly, we conducted a series of ANCOVAs, each of which examined the effects of parenting style, ethnicity, and the two-way interaction between parenting style and ethnicity on changes in the outcome variables of interest. For each analysis, the relevant Time 1 score was used as a covariate. In essence, the procedure allows for comparisons of change in each outcome across the 1-year period for youth from different types of families while taking into account differences in adjustment that were apparent at the first assessment, as well as the effects of regression to the mean.

These analyses were followed with simple pairwise post-hoc comparisons of the four parenting style groups. The post-hoc analyses controlled for ethnicity. For variables with significant parenting style $x$ ethnicity interaction effects, the analyses were repeated separately for each ethnic group to uncover ethnic differences in the effects of parenting style on change in outcomes across the 1-year period.

\section{Results}

The ANCOVAs indicated significant relations between parenting style and change in most of the measures of adolescent development assessed across a 1-year period. Table 5 presents the Time 1 outcome scores for each parenting style group, the adjusted change scores for each parenting style group, and information on the significance of the main effect of parenting style and the specific parenting style group contrasts.

\section{Parenting Style and Psychosocial Development}

Patterns of change in adolescents' selfreliance and work orientation, but not social competence, varied significantly over the 1-year period as a function of parenting style. Examination of the adjusted change scores and post-hoc contrasts revealed that, whereas authoritatively reared adolescents' self-reliance scores improved slightly over the 1-year period, those of youth from indulgent and authoritarian families essentially remained unchanged, while those of youth from neglectful homes generally declined somewhat. Similarly, whereas the work orientation scores of adolescents from neglectful and authoritarian homes declined over the year, those of adolescents from authoritative or indulgent homes remained more or less stable.

The interaction of parenting style with ethnicity was marginally significant $(p<.10)$ in the prediction of self-reliance. Follow-up analyses indicated that in the case of selfreliance, it was relatively more advantageous to be raised by indulgent parents among Asian-American youth than was the case among youngsters from other ethnic groups, and relatively more deleterious to be raised by authoritarian parents among European-American youth.

Although not central to the focus of this paper, analyses indicated a significant main effect of ethnicity on social competence. Follow-up analyses revealed that AfricanAmerican youth had more positive selfperceptions than did youngsters from each of the other three ethnic groups.

Parenting Style and Academic Competence

There were significant main effects of parenting style on patterns of change in academic self-conceptions and school orientation, but not grade point average, over the 1 


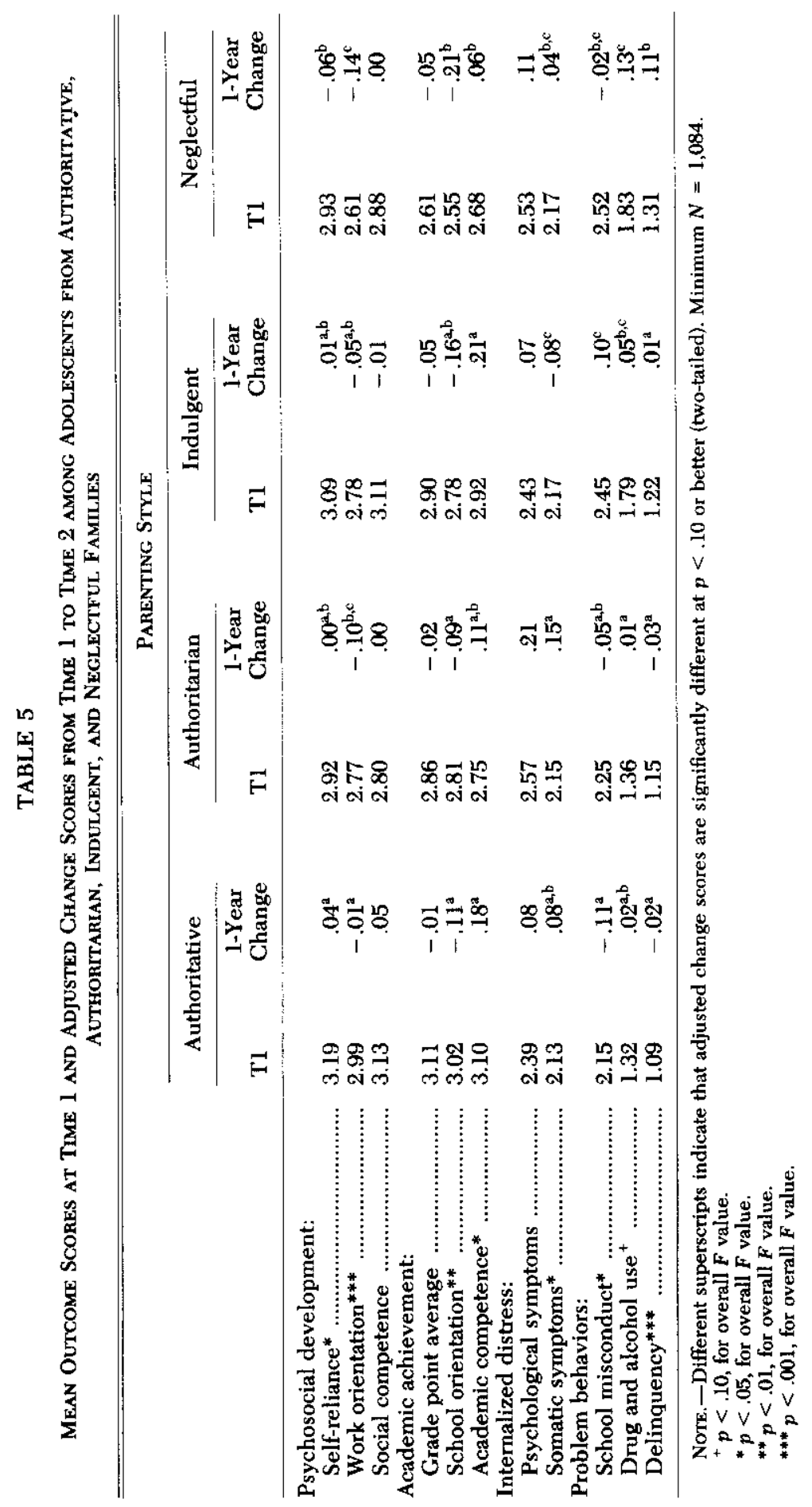




\section{Child Development}

year. Although academic self-conceptions became more positive over time in all four groups, the increase was significantly greater among authoritatively and indulgently reared youth than their counterparts from neglectful homes (the adolescents from authoritarian homes fell between the two extremes). And although all youngsters became somewhat more negative about school over time, the school orientation of neglectfully reared youth declined relatively more sharply, especially in comparison to that of youth from authoritative or authoritarian homes.

A significant parenting style $\times$ ethnicity interaction effect was detected in the prediction both of grade point average and academic self-conceptions, and a marginally significant interaction effect was detected in the prediction of school orientation. In general, whereas authoritative parenting was advantageous, and neglectful parenting disadvantageous, among European- and Hispanic-American youth, authoritarian parenting was relatively more advantageous among Asian-American youth and relatively more disadvantageous among European-American youngsters. Moreover, parenting style was unrelated to academic competence among African-American youth.

Although not central to this report, the analyses also indicated main effects for ethnicity on grade point average and academic competence, with grades of Asian-American youth increasing over the 1-year period and those of African-American and HispanicAmerican youngsters declining. The pattern of results for academic self-perceptions, however, showed that those of AfricanAmericans increased more than did those of other youngsters.

\section{Parenting Style and Behavior Problems}

Patterns of change over time in all three areas of problem behavior also varied as a function of parenting style, with significant effects for delinquency and school misconduct, and a borderline effect for drug and alcohol use. Youth with authoritative or authoritarian families either became less in. volved in problem behavior or reported no change across time, whereas rates of problem behavior either increased or remained more or less constant among youth from indulgent families and increased sharply among adolescents from neglectful homes.

The impact of parenting style on problem behavior did not vary across ethnic groups, There were significant ethnic differ- ences in drug and alcohol use, however, and marginally significant differences in delinquency. Specifically, drug and alcohol use increased more among European-American youth than other youngsters, and school misconduct decreased more among AsianAmerican youth than among their peers.

\section{Parenting Style and Internalized Distress}

Finally, the results indicated that patterns of change in reports of somatic distress, but not psychological symptoms, varied as a function of parenting style. Somatic symptoms increased most markedly among adolescents from authoritarian homes but decreased over time among indulgently raised youngsters. There were not significant twoway interactions between parenting style and ethnicity in the prediction of internalized distress, nor were there main effects for ethnicity in the prediction of psychological or somatic symptoms.

\section{Discussion}

Our previous report on the concurrent relation between parenting style and adolescent adjustment indicated clear advantages for adolescents raised in authoritative homes, clear disadvantages for their peers reared in neglectful homes, and mixed outcomes for adolescents from authoritarian or indulgent households (Lamborn et al., 1991). The results of this short-term followup indicate that many of the differences observed in the initial cross-sectional analyses are either maintained or increase over time. As a result, over the 1-year period studied here, the adjustment gap between adolescents from authoritative and neglectful homes widened.

Let us consider the patterns evinced by each of the four groups relative to their starting points. In our cross-sectional report, we noted that adolescents reared in authoritative families had advantages over other youngsters on measures of psychosocial competence, academic competence, inter nalized distress, and problem behaviors. The longitudinal analyses indicate overtime stability in most of these domains, with only two exceptions: academic selfconceptions, which improved, and school misconduct, which declined. Hence, it seems to be the case that the benefits of authoritative parenting during the high school years are largely in the maintenance of pre vious levels of high adjustment, rather than in the continued development of competence. 
A similar pattern of stability is seen among youngsters from authoritarian homes, with one important exception. While the disadvantages to adolescent self-confidence associated with authoritarian child rearing noted in our earlier report are maintained over time, youth from authoritarian homes showed significant increases in internalized distress over the 1-year period. One hypothesis is that the increased levels of psychological and somatic distress reported by these youngsters is tied somehow to their continued exposure to a home environment that is psychologically overpowering and increasingly developmentally inappropriate. Although the terminology differs, our characterization of the family environment of depressed or anxious adolescents as authoritarian is consistent with pictures of "overcontrolling" parents that emerge from clinical investigations (e.g., Stark, Humphrey, Cook, \& Lewis, 1990).

The adolescents from indulgent homes continued to display a psychological and behavioral profile that is mixed. In our cross-sectional report, we described these youngsters as well adjusted but "especially oriented toward their peers and toward the social activities valued by adolescents" (Lamborn et al., 1991, p. 1062). One year later, this description is even more apt: indulgently reared youth became more positive over time in their academic self-conceptions and reported less somatic distress, but at the same time they showed significant declines in school orientation and significant increases in school misconduct.

It is in the case of neglectfully reared adolescents, however, where we see the clearest evidence of the impact of parenting on adjustment during the high school years. These youth, already at a psychological and behavioral disadvantage at the time of first assessment, showed continued declines over the 1-year period, with sharp drops in work orientation and school orientation, and sizable increases in delinquency and alcohol and drug use. The overall pattern suggests a group of youngsters on a downward and troublesome trajectory characterized by academic disengagement and problem behavior.

This study followed adolescents over the course of 1 year-perhaps not a long enough period of time during which to observe marked changes in the sorts of outcomes assessed in this study. We think it important, therefore, to consider the magnitude of the changes we have observed by examining each group's adjusted change scores in relation to the relevant variable's standard deviation. In doing so, we see that many of the observed changes are not trivial. In the case of school orientation and work orientation, for instance, the scores of neglectfully reared youngsters declined by about onethird of a standard deviation over just 1 year, while their delinquency and substance use increased by about one-fourth of a standard deviation (see Figs. 1 and 2). Youngsters from authoritarian homes reported an increase in internalized distress of approximately one-fourth of a standard deviation over the year (see Fig. 3). And on the positive side, the academic self-conceptions of authoritatively and indulgently reared youngsters increased by approximately onethird of a standard deviation in 1 year (see Fig. 4). If changes of similar magnitude were to occur each year over the course of adolescence, the end result would indeed be noteworthy. Further longitudinal research over a longer time frame will help provide clearer pictures of the different developmental trajectories of youngsters who have been exposed to different parenting styles.

Our ability to demonstrate that the overtime impact of parenting style on adolescent adjustment holds even after controlling for initial group differences is important for several reasons. First, in the absence of a randomized experimental design, the analytic strategy employed here provides at least indirect evidence that authoritative parenting actually precedes-rather than simply accompanies or even follows from-adolescent adjustment. (Because one can not randomly assign adolescents to different home environments, such indirect evidence is important.) This is not to say that our analyses rule out the possibility that the reverse causal process is operating simultaneously (i.e., that well-adjusted adolescents also provoke authoritativeness in their parents); given past research on the bidirectional nature of socialization (e.g., Bell, 1968), it almost certainly is. (Unfortunately, the absence of comparable parenting assessments in the second year of the investigation precluded our examining the impact of adolescents on their parents.) What the present results provide, however, is evidence that the correlation between adolescent adjustment and parenting style is not solely due to the effect that children have on their parents. At least some of it is due to the impact that parents have on their children. 


\section{Child Bevelopment}

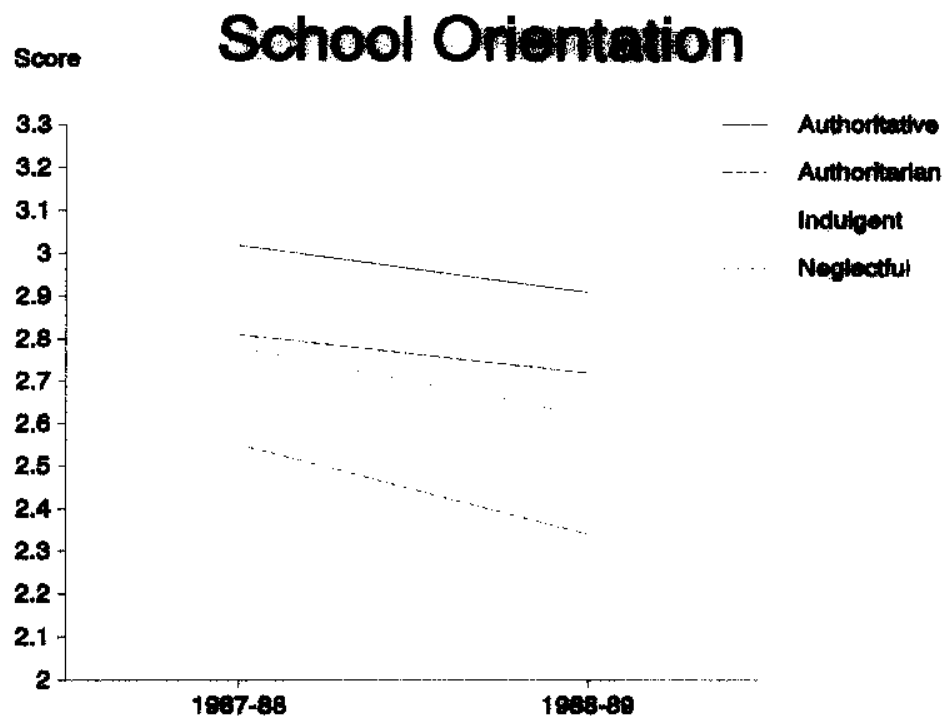

FIG. 1.-Changes in adolescent school orientation as a function of parenting style

A second advantage of our analytic strategy concerns our ability to respond to criticisms that the observed correlations between parenting style and adolescent adjustment are due simply to common source or method variance, problems that inherently threaten the internal validity of research designs that rely on self-reports from one respondent. The source and method variance shared in common between adolescents' characterizations of their parents in the first year of the study and their self- reports of adjustment 1 year later is also shared in common between their parental characterizations in the first year and their self-reports of adjustment assessed concurrently. (Indeed, given the common time of measurement, the shared source and method variance is likely to be even more substantial for concurrent measures.) Due to the high 1-year stability coefficients for the adjustment measures (most are greater than .60 ), controlling for subjects' initial adjustment self-reports has the effect of partialing

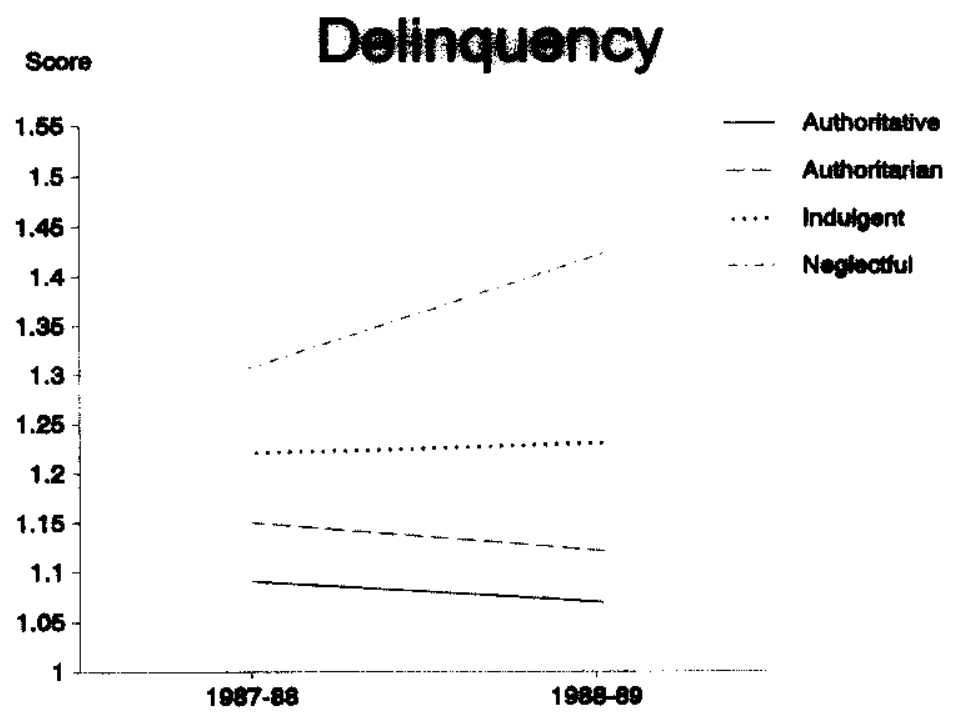

FIG. 2.-Changes in adolescent delinquency as a function of parenting style 
Steinberg et al. $\quad 767$

\section{Score \\ Somatic Symptoms}

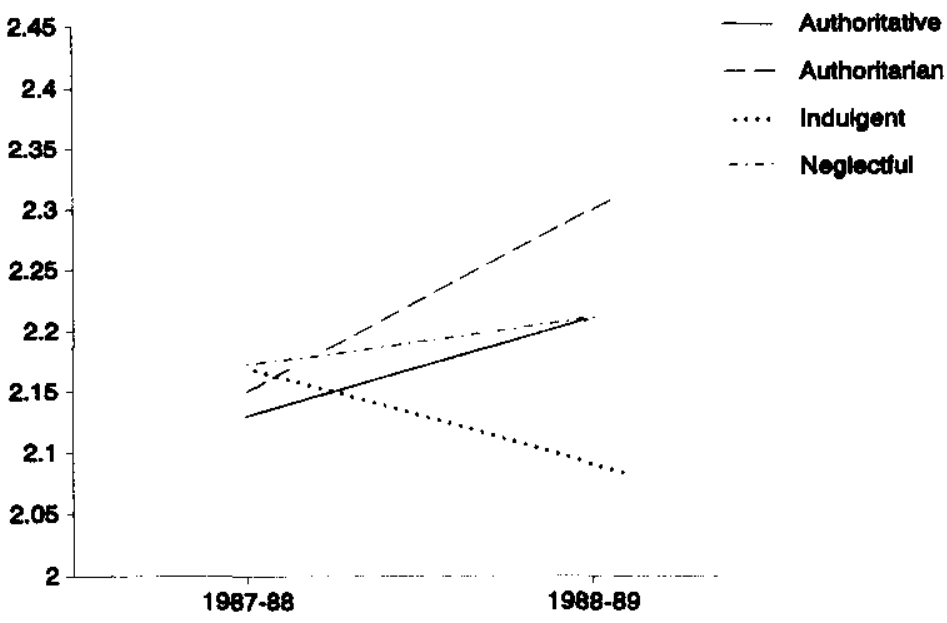

FIG. 3.-Changes in adolescent somatic symptoms as a function of parenting style

out much of the common method and source variance.

Finally, the covariance analyses employed here help rule out many potential third-variable explanations of the over-time association between parenting style and adolescent adjustment. Any such alternative account would necessarily have to posit the existence of a confounding variable that is correlated with the measures of adjustment in the study's second year but that was not correlated with the same measures taken just
1 year earlier. As a test of this possibility, we compared the correlation between parental education (a likely confounding variable) and the Time 1 versus Time 2 measure of each of the outcome variables used in the study. In every case, the correlation coefficient was virtually identical at Time $I$ and at Time 2. While it is of course theoretically possible that there exists some other, unmeasured, third variable that is differentially correlated with the outcome measures at Time 1 and Time 2, it seems more parsimonious-and far more plausible, given other

\section{sore Academic Competence}

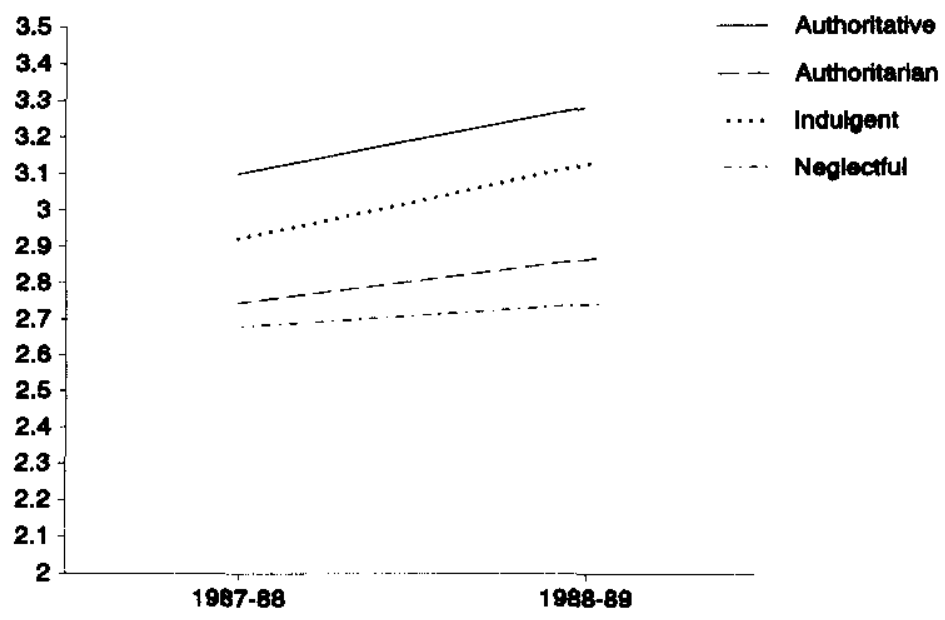

Fic. 4.-Changes in adolescent academic competence as a function of parenting style 
studies in the socialization literature-to accept the observed association between parenting practices and adolescent adjustment as internally valid.

Despite these strengths, the study does have several weaknesses. First, as discussed earlier, our decision to focus on the extreme quadrants in the sample in order to ensure that we were contrasting different parenting types limits somewhat the external validity of our findings. Although our approach provides a reasonable test of Maccoby and Martin's (1983) framework, we cannot be certain that contrasts based on a less extreme categorization scheme would yield the same results. It is important to bear in mind, however, that the extreme groups studied here-and, most important, the "neglectful" group-are drawn from a representative community sample and not obtained through clinics or similar nonrepresentative sources.

A second weakness is that all of the data derive from youngsters' self-reports. While the nature of the analyses does argue against explanations based on common source and method variance (as discussed above), our findings can be interpreted only to show that adolescents' adjustment is related to the way in which they subjectively experience their parents. Although we recognize that youngsters' reports of their parents' behavior may be colored by a variety of factors, we do not believe that "objective" assessments of family processes (derived in most studies by observing families in contrived and unfamiliar situations in university laboratories) or parental reports provide an inherently superior means of assessing family relationships. Indeed, the few studies that have correlated "objective" assessments of family life with both adolescents' reports of their parents' behavior and with their parents' reports suggest that adolescents, not parents, are more accurate (e.g., Schwartz, Barton-Henry, \& Pruzinsky, 1985). Perhaps more important, our willingness to use adolescents' reports permits us to study a more representative sample than would be the case if parents' participation in the study were required. Nevertheless, we recognize that it also is important to investigate the relation between parenting and adolescent adjustment using multiple methods and different sources of information.

Although not a focus of this report, we find that patterns of change in adolescent adjustment vary by ethnicity. Most of the find- ings in this regard are consistent with other reports of ethnic differences in adolescent development and behavior, specifically, (1) Asian-American youth report the greatest improvement in school performance, whereas the academic performance of African-American and Hispanic-American youth showed the greatest decline (see Steinberg, Dornbusch, \& Brown, 1992), (2) AfricanAmerican youth report the most positive changes in self-perceptions (see Spencer \& Dornbusch, 1990), and (3) EuropeanAmerican youth report the greatest increases in drug and alcohol use (see Gans, 1990).

More interestingly, several of the effects of parenting style appear to be moderated by the adolescent's ethnicity. Generally speaking, the links between authoritative parenting and both psychosocial and academic competence appear to be strongest among European-American youth. In light of the fact that authoritativeness is a characteristically Western and middle-class approach to child rearing, the fact that it may have greater advantages in these groups is not surprising, since the style may be more consonant with other elements of family life. In addition, in the contemporary United States, authoritativeness is more prevalent among European-American and middleclass families, and authoritatively reared youngsters from these backgrounds may be more likely to have these practices echoed (and, presumably, amplifed) in their neighborhoods and social networks than are authoritatively reared youngsters from other ethnic or class backgrounds (Steinberg \& Darling, 1994).

It is important to note also that the putative deleterious consequences of parental authoritarianism are evidently not as severe among minority youth as among their European-American counterparts. We note this finding in particular because the suggestion is not new that minority youngstersespecially those from economically disadvantaged backgrounds-may benefit from a relatively more authoritarian style of parenting (see Baldwin \& Baldwin, 1989; Baumrind, 1972; Dornbusch et al., 1987; but see Clark, 1983, for a contrasting view). One hypothesis is that authoritarianism may be more beneficial among families whose living circumstances warrant stricter, more vigilant control. Another, equally tenable hypothesis is that the meaning of authoritarianism-or any parenting style, for that matter-is moderated by the cultural context in which it occurs and, consequently, interpreted differ- 
entially by children from different ethnic or socioeconomic groups. Accordingly, what may be experienced by the adolescent as parental intrusiveness in some cultural groups may be experienced as parental concern in others (see Darling \& Steinberg, 1993).

It is important to bear in mind, however, that in some domains-most notably, problem behavior and internalized distressauthoritativeness appears to confer comparable benefits across varied ecological niches (see also Steinberg et al., 1991). Moreover, we are hard pressed to find any groups within which authoritativeness has deleterious consequences for the adolescent, or any groups in which neglectful or disengaged parenting is desirable. On the whole, then, it appears that the combination of parental aloofness and disciplinary laxity appears universally harmful to adolescents. Conversely, parental authoritativeness-the combination of responsiveness and demandingness-carries many benefits and few disadvantages for adolescents from different walks of life.

\section{References}

Baldwin, C., \& Baldwin, A. (1989, April). The role of family interaction in the prediction of adolescent competence. Symposium presented at the meeting of the Society for Research in Child Development, Kansas City, MO.

Baumrind, D. (1967). Child care practices anteceding three patterns of preschool behavior. Genetic Psychology Monographs, 75, 43-88.

Baumrind, D. (1971). Current patterns of parental authority. Developmental Psychology Monograph, 4(1), part 2.

Baumrind, D. (1972). An exploratory study of socialization effects on black children: Some black-white comparisons. Child Development, 43, 261-267.

Baumrind, D. (1991). The influence of parenting style on adolescent competence and substance use. Journal of Early Adolescence, 11 , $56-95$.

Bell, R. (1968). A reinterpretation of the direction of effects in studies of socialization. Psychological Review, 75, 81-95.

Clark, R. (1983). Family life and school achievement: Why poor black children succeed or fail. Chicago: University of Chicago Press.

Darling, N., \& Steinberg, L. (1993). Parenting style as context: An integrative model. Psychological Bulletin, 113, 487-496.

Donovan, J., \& Jessor, R. (1985). Structure of problem behavior in adolescence and young adulthood. Journal of Consulting and Clinical Psychology, 53, 890-904.
Dornbusch, S., Carlsmith, J., Bushwall, S., Ritter, P., Leiderman, P., Hastorf, A., \& Gross, R. (1985). Single parents, extended households, and the control of adolescents. Child Development, 56, 326-341.

Dornbusch, S., Ritter, P., Liederman, P., Roberts, D., \& Fraleigh, M. (1987). The relation of parenting style to adolescent school performance. Child Development, 58, 1244-1257.

Gans, J. (1990). America's adolescents: How healthy are they? Chicago: American Medical Association.

Gold, M. (1970). Delinquent behavior in an American city. Belmont, CA: Brooks/Cole.

Greenberger, E., Josselson, R., Knerr, C., \& Knerr, B. (1974). The measurement and structure of psychosocial maturity. Journal of Youth and Adolescence, 4, 127-143.

Greenberger, E., Steinberg, L., \& Vaux, A. (1981). Adolescents who work: Health and behavioral consequences of job stress. Developmental Psychology, 17, 691-703.

Harter, S. (1982). The Perceived Competence Scale for Children. Child Development, 53, 87-97.

Hetherington, E. M., Clingempeel, W., Anderson, E., Deal, J., Hagan, M., Hollier, E., \& Lindner, M. (1992). Coping with marital transitions: A family systems perspective. Monographs of the Society for Research in Child Development, 57(2-3, Serial No. 227).

Jessor, R., \& Jessor, S. (1977). Problem behavior and psychosocial development: A longitudinal study of youth. New York: Academic Press.

Laird, N. (1983). Further comparative analyses of pretest-posttest research designs. American Statistician, 37, 329-330.

Lamborn, S., Mounts, N., Steinberg, L., \& Dornbusch, S. (1991). Patterns of competence and adjustment among adolescents from authoritative, authoritarian, indulgent, and neglectful homes. Child Development, 62, 10491065.

Maccoby, E., \& Martin, J. (1983). Socialization in the context of the family: Parent-child interaction. In E. M. Hetherington (Ed.), P. H. Mussen (Series Ed.), Handbook of child psychology: Vol. 4. Socialization, personality, and social development (pp. 1-101). New York: Wiley.

McCord, J. (1990). Problem behaviors. In S. Feldman \& G. Elliot (Eds.), At the threshold: The developing adolescent (pp. 414-430). Cambridge, MA: Harvard University Press.

Patterson, G., \& Stouthamer-Loeber, M. (1984). The correlation of family management practices and delinquency. Child Development, 55, 1299-1307.

Radloff, L. S. (1977). The CES-D Scale: A self- 
report depression scale for research in the general population. Applied Psychological Measurement, 1, 385-401.

Rodgers, R. R. (1966). Cornell Parent Behavior Description-an interim report. Unpublished manuscript, Department of Human Development and Family Studies, Cornell University, Ithaca, NY.

Ruggiero, M. (1984). Work as an impetus to delinquency: An examination of theoretical and empirical connections. Unpublished doctoral dissertation, University of California, Irvine.

Schaefer, E. (1965). Children's reports of parental behavior: An Inventory. Child Development, 36, 413-424.

Schwartz, J., Barton-Henry, M., \& Pruzinsky, T. (1985). Assessing child-rearing behaviors: A comparison of ratings made by mother, father, child, and sibling on the CRPBI. Child Development, 56, 462-479.

Spencer, M., \& Dormbusch, S. (1990). Challenges in studying minority youth. In S. Feldman \& G. Elliot (Eds.), At the threshold: The developing adolescent (pp. 123-146). Cambridge, MA: Harvard University Press.

Stark, K., Humphrey, L., Cook, K., \& Lewis, K. (1990). Perceived family environments of depressed and anxious children: Child and maternal figures' perspectives. Journal of Abnormal Child Psychology, 18, 527-547.

Steinberg, L. (1990). Interdependency in the family: Autonomy, conflict, and harmony. In S. Feldman \& G. Elliot (Eds.), At the threshold: The developing adolescent (pp. 255-276). Cambridge, MA: Harvard University Press.
Steinberg, L., \& Darling, N. (1994). The broader context of adolescent development. In $\mathbf{R}$. Silbereisen \& E. Todt (Eds.), Adolescence in context (pp. 25-45). New York: SpringerVerlag.

Steinberg, L., Dornbusch, S., \& Brown, B. (1992). Ethnic differences in adolescent achievement: An ecological perspective. American Psychologist, 47, 723-729.

Steinberg, L., Elmen, J., \& Mounts, N. (1989). Authoritative parenting, psychosocial maturity, and academic success among adolescents. Child Development, 60, 1424-1436.

Steinberg, L., Lamborn, S., Dombusch, S., \& Darling, N. (1992). Impact of parenting practices on adolescent achievement: Authoritative parenting, school involvement, and encouragement to succeed. Child Development, 63, 1266- 1281.

Steinberg, L., Mounts, N., Lamborn, S., \& Dornbusch, S. (1991). Authoritative parenting and adolescent adjustment across various ecological niches. Journal of Research on Adolescence, 1, 19-36.

Wehlage, G., Rutter, R., Smith, G., Lesko, N., \& Fernandez, R. (1989). Reducing the risk: Schools as communities of support. London: Falmer.

Weinberger, D., Tublin, S., Ford, M., \& Feldman, S. (1990): Preadolescents' social-emotional adjustment and selective attrition in family research. Child Development, 61, 1374-1386. 
This document is a scanned copy of a printed document. No warranty is given about the accuracy of the copy. Users should refer to the original published version of the material. 